\title{
A psicologia fenomenológica e a filosofia de Buber: o encontro na clínica'
}

\section{Phenomenological psychology and Buber's philosophy: the encounter at the clinical practice}

\author{
Giovana Fagundes LUCZINSKI² \\ Marília ANCONA-LOPEZ3
}

\begin{abstract}
Resumo
Este artigo trata de reflexões empreendidas no âmbito da psicologia clínica de orientação fenomenológica. No aprofundamento da concepção de homem proposta por esta perspectiva, fundamenta-se um tipo de clínica centrada na pessoa enquanto singularidade articuladora das dimensões biopsicossocial e espiritual, ontologicamente voltada para a compreensão de si e do mundo. A filosofia de Martin Buber complementa a proposta fenomenológica, ressaltando a potencialidade da relação humana na sua concretude e movimento. São analisadas as noções de relação eu-tu, eu-isso e encontro, nas suas implicações para a prática clínica, propondo-se reflexões sobre o lugar do psicólogo na interação com o cliente. Busca-se, com este diálogo, delinear um atendimento psicológico a partir do cuidado com a pessoa em sua totalidade, facilitando seu movimento incessante de integrar-se e transformar-se mediante o encontro genuíno com o outro.
\end{abstract}

Unitermos: Fenomenologia. Psicologia clínica. Psicoterapia.

\begin{abstract}
The present article introduces a number of considerations in the area of phenomenological orientation in clinical psychology. Going more deeply into the concept of man proposed by this perspective, a type of clinic is founded revolving around the person as a singular individual articulating the biological, psychological, social and spiritual dimensions, who is ontologically moved towards the understanding of himself and the world. Martin Buber's philosophy complements the phenomenological proposal, emphasizing the potentiality of the human relation seen in its concreteness and movement. The concepts of the l-Thou relation, I-It relation and Encounter are analyzed in terms of their implications for the clinical practice, proposing reflections about the function of the psychologist in the interaction with the patient. We intend, with this discussion, to delineate a psychological treatment based on the care of the individual in his totality, facilitating his incessant movement towards fitting in and transforming himself through genuine Encounters with anotherindividual.
\end{abstract}

Uniterms: Phenomenology research. Clinical psychology. Psychotherapy.

\section{$\boldsymbol{\nabla \nabla \nabla \nabla}$}

1 Artigo elaborado a partir da dissertação de G.F. LUCZINSKI, intitulada "O psicólogo clínico e a religiosidade do cliente: impactos na relação terapêutica". Pontifícia Universidade Católica de São Paulo, 2005. Apoio: Coordenação de Aperfeiçoamento de Pessoal de Nível Superior.

2 Consultório - Espaço de Psicologia. R. Hilário de Gouveia, 66, Sala 504, Copacabana, 22040-900, Rio de Janeiro, RJ, Brasil. Correspondência para/Correspondence to: G.F. LUCZINSKI. E-mail: <giovana.luczinski@gmail.com>.

3 Pontifícia Universidade Católica de São Paulo, Faculdade de Ciências Humanas e da Saúde, Programa de Estudos Pós-Graduados em Psicologia Clínica. São Paulo, SP, Brasil. 
No exercício da prática clínica, o psicólogo procura compreender o homem no mundo, buscando uma forma de acompanhá-lo em suas necessidades, com objetivos terapêuticos. Desta forma, emerge o questionamento cada vez mais profundo sobre quem é o homem e o que pode o psicoterapeuta fazer por ele, ou com ele, com os recursos de que dispõe. Para tentar responder a estas questões é fundamental tecer pontes entre a psicologia e a filosofia, cujos questionamentos iluminam pontos cruciais da existência humana, apontando horizontes a serem explorados no âmbito psicológico. No entanto, tal aproximação deve ser crítica e cuidadosa, pois são abordados diferentes campos do saber, cujos conceitos não podem ser diretamente transpostos de uma área para outra.

Este artigo é fruto de reflexões nesse sentido, partindo de inquietações diante do encontro humano na clínica de orientação fenomenológica. O percurso aqui traçado busca explicitar uma visão de homem eminentemente relacional, calcada na fenomenologia e em suas implicações para a constituição de uma clínica mais dialógica. Para isso, as contribuições de Martin Buber, o filósofo da relação, são fundamentais, pois suas concepções de homem e de realidade complementam a proposta fenomenológica, ao partir da ontologia para compreender a ação humana no mundo e a transformação a partir do encontro com o outro. Como Buber é um filósofo, a transposição de seus conceitos para o campo dos fenômenos psíquicos exige reflexões críticas e comparações com as vivências na prática. Desta forma, torna-se importante repensar a relação eu-tu no âmbito da clínica e o papel do encontro no processo psicoterapêutico, dialogando com autores que empreenderam tais aproximações.

\section{O ser humano na perspectiva fenomenológica}

A psicologia fenomenológica utiliza conceitos e concepções vindos de uma tradição filosófica - a fenomenologia - alterados em linguagem psicológica e colocados em interação com a teoria e a prática dos atendimentos. Para alcançar maior rigor e coerência, é preciso, inicialmente, recorrer à concepção de homem desta proposta, explicitando-a.

Para a fenomenologia, cada ser possui uma 76 especificidade ontológica, o que implica diferentes formas de se manifestar no mundo e de realização de si (Critelli, 1996). O homem é ontologicamente diferente dos demais seres, tendo recebido, na sua humanidade, condições específicas para dar conta da própria vida, sustentá-la e ampliá-la. Ele é um feixe de possibilidades, sempre em aberto, podendo transcender e surpreender a si mesmo, lançado no mundo sem o controle da vida e sem certezas sobre o seu destino. Assim, por mais que busque a estabilidade e a segurança de diversas formas ao longo da história, o homem está sempre diante de questões existenciais que o desestabilizam e o colocam em movimento. É um ser em constante construção, o que se dá a partir do contato com os outros, na coexistência. Ele é único e irrepetível, ao mesmo tempo em que herda toda uma cultura construída ao longo do tempo por muitos outros, seus semelhantes. Singularidade e pluralidade convivem lado a lado na difícil tarefa de habitar o mundo e transformá-lo (Arendt, 1971; Critelli, 1996).

Estas características específicas do ser humano delimitam uma ontologia, que se mostra na sua totalidade, mas que possui uma estrutura compreendida nas dimensões biopsicossocial e espiritual. A dimensão biológica se expressa na corporeidade, à qual o homem está definitivamente atrelado enquanto vive. O corpo é um instrumento, uma morada e um limite, algo que o conecta à concretude do mundo. É também a forma pela qual seu ser se manifesta, apresentando-se externamente de forma singular entre os demais da mesma espécie, sendo ao mesmo tempo limite e abertura para o mundo, através da percepção (Arendt, 1971).

A dimensão psíquica, por sua vez, refere-se à forma como a pessoa vivencia sua existência no mundo, motor de suas ações e sentimentos. Segundo Ales Bello (2004), os atos psíquicos são atos de reação, pertencentes ao campo da afetividade e das emoções. Impactar-se com o mundo ao redor e responder a ele é uma capacidade inerente a todos os seres humanos, porém, a que fenômenos reagem, o conteúdo e o modo dessas reações serão diferentes para cada um. Há, portanto, uma estrutura comum que permite afirmar que alguém vivencia algo com um outro, embora os conteúdos sejam singulares.

A dimensão social consiste no fato de ser com os outros: a pessoa constitui a história humana e é constituída por ela. Aqui, é fundamental a herança cultural, 
diante da qual o homem tem uma postura ativa, recebendo e transformando o que lhe é dado. Cada época histórica, com suas peculiaridades, condiciona diferentes modos de responder e de se relacionar com a realidade. Nesse movimento, presente em todas as culturas e gerações, o encontro intersubjetivo possibilita que as pessoas sejam tocadas e transformadas, sendo coautoras das trajetórias umas das outras. Segundo Merleau-Ponty (1945/1999), o social existe como um campo permanente, consistindo em uma solicitação, antes mesmo da tomada de consciência em relação ao mundo.

Por fim, há o nível espiritual, também presente em todas as manifestações humanas cotidianas. Para Ales Bello (2004), nele estão contidas todas as experiências ligadas à razão e à vontade. São atividades que se diferenciam daquelas relativas ao psiquismo, pois podem as pessoas controlá-las através da reflexão e da decisão. "A esfera espiritual é também uma esfera valorativa" (Ales Bello, 2004, p.250) e nela são produzidos e conferidos significados à realidade. Para Mahfoud e Coelho (2001), a dimensão espiritual está ligada à vivência da liberdade e da responsabilidade, pois implica um posicionamento da pessoa diante das reações que a acometem.

O nível espiritual engloba, ainda, a questão do mistério que atravessa as experiências humanas, apontando para a capacidade de transcendência. O homem sempre transcende a si mesmo, por estar continuamente voltado para algo ou alguém fora de si. Nesse movimento, busca também ultrapassar os limites do mundo sensível e relacionar-se com seres que situa em outra ordem, como deuses, espíritos, energias cósmicas, entre outros. Buscando significar sua existência, o homem se pergunta sobre o sentido último da vida ou a que esta se destina, dentro ou além do período de tempo que a abarca.

Hycner (1995) considera o nível espiritual fundamental para a psicoterapia, afirmando a existência, além das dimensões intrapessoal e interpessoal, do nível transpessoal. Este se manifesta na medida em que as pessoas estão permanentemente conectadas umas às outras também no registro espiritual. Na perspectiva buberiana (Buber, 1923/2001), não é através da transcendência da realidade mundana que se chega ao nível espiritual, mas justamente estando imerso nesta, a partir da relação com o outro.
Ao elaborar suas vivências e conferir sentidos ao mundo, singularizando-se, a pessoa transita entre as diversas dimensões. Para que os conteúdos do psiquismo se expressem, eles precisam de um lugar que veicule tais reações e as tornem visíveis e sensíveis, e este lugar é o corpo. A própria percepção tem sua origem na corporeidade, nos sentidos. No entanto, para que uma pessoa avalie como reais suas percepções, é preciso que exista um expectador, alguém com quem compartilhar o fenômeno vivido. É preciso um reconhecimento, pois o homem não se faz sozinho, e sim na coexistência. Paralelamente a este processo, a pessoa constitui valores e crenças, exercendo a vontade, a liberdade e a responsabilidade, dentro dos seus limites. Assim, novos sentidos são construídos e decisões são tomadas sobre a própria vida. Há, portanto, uma inseparabilidade das quatro dimensões humanas: o homem é de fato um ser biopsicossocial e espiritual, construindo-se de forma integrada. O que interessa para a psicologia aqui proposta, então, é como cada pessoa se diferencia das demais, como se singulariza, mesmo tendo uma estrutura semelhante, sendo lançada no mundo com as mesmas condições ontológicas. Importa como cada uma sustenta a própria vida e coloca em trânsito seu processo de crescimento.

O homem dá significado ao mundo e a si próprio em todos os níveis. Segundo Augras (1986), "a compreensão não é um mero instrumento de apreensão do mundo, mas uma dimensão ontológica da existência" (p.24). Isso é fundamental para a psicologia fenomenológica, que privilegia essa característica inerente ao homem de elaborar continuamente sua condição. Por isso, ao olhar o ser humano em toda a sua diversidade, na clínica, abre-se a possibilidade de perceber fenômenos que não são considerados psíquicos, mas interferem nesta esfera, ou simplesmente coexistem na vida da pessoa. Safra (2004a) ressalta a importância dessa constatação, assinalando que há sofrimentos que alcançam o registro psíquico, mas não têm sua origem neste, pois os seres humanos são atravessados por toda a história e suas questões, em seus múltiplos aspectos.

A escolha da abordagem fenomenológica enquanto orientação existencial, postura e método de intervenção na clínica psicológica permite considerar todas as dimensões do ser humano, facilitando o talhamento de um olhar e a consolidação de uma postura 
em direção ao outro. Tal abordagem, por trazer no cerne da sua proposta a pergunta sobre quem é o Homem, amplia a percepção do terapeuta, permitindo acolher os modos de ser daqueles que o procuram, contribuindo para que a psicoterapia seja a possibilidade de um encontro real e transformador.

\section{Delineando uma proposta clínica}

O profissional imbuído da concepção de homem descrita anteriormente buscará, no exercício da psicologia, acolher a pessoa nas suas dimensões biopsicossocial e espiritual, ajudando-a a elaborar suas experiências, integrando estas esferas. Essa integração só é possível no encontro com outra pessoa, sendo o terapeuta alguém que propõe um tipo de relação que abra as possibilidades de transformação inerentes à condição humana. A presença do terapeuta, então, torna-se a primeira e talvez a sua principal intervenção ao longo de todo o processo.

Certamente, a pessoa pode entrar em um processo de crescimento e mudança a partir de diferentes encontros e experiências ao longo da vida, sem que haja relação com a psicologia. Mas quando há um atendimento psicológico, faz-se necessário aprofundar a dimensão do encontro entre terapeuta e cliente, explicitando os elementos presentes nesta interação. Para isso, as colocações da psicologia devem ser postas em diálogo com aquelas da filosofia que são relevantes para este tema. Entre os pensadores que se dedicaram intensamente à questão da coexistência, encontra-se Martin Buber, o filósofo da relação. Em toda a sua obra, há grande preocupação com a ontologia e a antropologia na teorização da relação humana, do encontro pessoa-pessoa. Seguindo seus passos, diversos psicólogos promoveram desdobramentos das suas ideias com aplicações clínicas.

\section{Considerações sobre a relação eu-tu}

As ideias de Martin Buber contribuem para a integração de uma concepção filosófica do ser humano a uma atitude diante deste. Em sua obra, Buber trata do homem no mundo, de suas múltiplas possibilidades de existir, dependendo de como se coloca. As palavras-

78 -princípio eu-tu e eu-isso assinalam modos de ser do homem, formas de responder à realidade, que sempre solicita um posicionamento. $\mathrm{O}$ eu que se abre para um tu não é como o eu que se relaciona com um isso, ou seja, a forma de relacionamento estabelecida fundamenta o modo de ser. Por isso, a relação produz diferentes possibilidades de a pessoa estar no mundo. Eu-tu e eu-isso são parte do movimento humano, sendo inseparáveis, alternando-se constantemente a cada relacionamento (Buber, 1923/2001).

Na atitude eu-tu, a pessoa entra em relação, deixa-se impactar, deixa-se atravessar pela presença viva do outro, seja este outro uma pessoa, uma situação, uma obra ou um ente qualquer. Há nesse instante uma dimensão intensiva, não mensurável ou redutível à temporalidade, espacialidade e questões objetivas. $O$ mundo do tu não tem coerência no espaço e tempo: é um campo de forças, de presença, de vitalidade. Não pode ser apreendido ou aprisionado em representações: sempre escapa. Não se reduz à percepção: é intenso, vivo, pulsante. Sempre ressurge diferentemente, em contínua transformação.

A atitude eu-isso, por sua vez, leva a experienciar de forma objetiva as situações. O mundo do isso ou da objetividade ordena o real, transformando-o em habitável e reconhecível. Para Buber (1923/2001), a melancolia do destino humano é que o tu se torna, irremediavelmente, um isso, o que é necessário para a compreensão do processo vivido. Não se consegue manter sempre a atitude eu-tu, pois o homem é incapaz de habitar permanentemente no encontro. A existência é pautada pela alternância entre as atitudes eu-tu, eu-isso e seus desdobramentos.

Na perspectiva buberiana, a experiência implica um distanciamento reflexivo, situando-se no âmbito do isso, enquanto a relação está no âmbito do tu. A relação é vivência, não experiência. Ao encontrar alguém no modo eu-tu, a consequente perda do espaço, do tempo e a desestabilização do eu possibilitam contemplação, novas sensações, atravessamentos. A relação eu-isso, ao contrário, situa a pessoa no mundo dos objetos, ordenando e sendo extremamente necessária para a elaboração e a produção de significados, desde que não se torne a forma predominante de relação com o mundo. Para Merleau-Ponty (1945/1999), ao perceber o outro apenas como um isso, objetificando-o, há um afastamento da sua presença viva. Segundo este autor, 
acessar o outro como representação é desconsiderar a sua humanidade, a vida que Ihe é dada enquanto homem. A relação com o outro não se dá a partir de um esquema mental prévio, anterior, mas implica estar disponível para ele assim como se mostra naquele momento, deixando de lado preconcepções. Na clínica, a interação eu-isso limita o psicólogo à utilização da técnica, a uma consideração dos sintomas meramente a partir de propostas teóricas, sem levar em conta as particularidades da pessoa e sua complexidade.

Ao postular sobre a relação e seus modos de acontecer, Buber considera o homem como ação no mundo. Sua disposição para entrar em contato com o outro tem consequências na própria vida, imprimindo-se no seu modo de ser. Há uma escolha, consciente ou não, de se deixar tocar pela presença viva da alteridade, sofrendo os efeitos deste impacto. Nessa perspectiva, a palavra proferida no diálogo é um gesto que se inscreve no mundo, é ação. Por esse motivo, a palavra falante, nascida no encontro verdadeiro, atualiza o ser do homem, transforma-o. Ao falar, uma mudança é produzida e, no contato intersubjetivo, surgem novos modos de subjetivação. A palavra é possibilitadora do ser e sua força transformadora se concretiza no "entre". O "entre" constitui um espaço de trocas, algo que não pertence a nenhum dos participantes: pertence a ambos e os ultrapassa. É a dimensão de mistério no encontro humano, que transcende os envolvidos e aponta para novas possibilidades de ser e de estar no mundo. É importante lembrar que, para Buber, esse nível não pode se limitar ao intrapsíquico: o diálogo é algo que ocorre entre as pessoas, e não dentro delas. É voltar-se para o outro, para o mundo e, então, poder ver-se enquanto um eu e ao outro enquanto um tu (Buber, 1923/2001).

A concepção buberiana sobre a relação pode remeter à prática clínica, pois ajuda a compreender o fascínio que trabalhar calcado nesse tipo de concepção exerce nos psicólogos que a adotam. Ao conseguir se abrir para o cliente de forma a conseguir acessá-lo enquanto um tu, institui-se uma forma de relação em que o terapeuta pode entrar no modo eu-tu de funcionamento, ou seja, torna-se um eu. Pode ser um eu porque diz tu, considerando o outro enquanto presença e, assim, seu eu já não é o mesmo - é um eu em relação, torna-se também gesto, sofre uma transformação. Por isso, a relação entre terapeuta e cliente pode ser algo tão fecundo, sendo seguida, muitas vezes, de uma sensação indescritível de admiração e plenitude. É um sentimento fugaz, mas com consequências também para o terapeuta. É como se fosse realmente uma ruptura do funcionamento comum e uma abertura sutil para a dimensão ontológica que envolve todos os seres. Acreditar que o cliente possa viver algo assim, mesmo que isso não se dê de forma reflexiva ou constante, alimenta o interesse por esta perspectiva humana, ampliando as possibilidades de um atendimento para além da técnica e do psicologismo.

Experimentar novos modos de ser em presença de um outro é uma ação que deixa marcas. Ao mesmo tempo em que é algo intenso e prazeroso, este acontecimento deixa mais questões do que conforto e satisfação, abalando a segurança da pessoa. Ela é lançada ao encontro de um terceiro elemento, o espaço do "entre", que a leva ao contato consigo mesma e com o outro, abalando as estruturas já construídas, trazendo certa vertigem. Mesmo assim, a relação é buscada incessantemente, apontada por Buber como uma necessidade inata do ser humano, o caminho para seu crescimento, pois a relação eu-tu confronta, provoca e remete ao paradoxo da existência. No diálogo genuíno, tanto no que é mutuamente construído e buscado quanto na relação espontânea a vivência eu-tu pode ocorrer, abrindo e transformando. Buber admite e explicita a fugacidade dos momentos eu-tu em meio à atitude eu-isso, mas assinala aquilo que todos percebem ao vivenciar encontros: quando acontecem, seus efeitos são inegáveis.

Ao partilhar esta visão, é preciso pensar profundamente a relação que se dá no processo de psicoterapia e em que medida esta pode facilitar o encontro verdadeiro. Amatuzzi (1989), ao avaliar a importância dada por Buber à mutualidade na relação eu-tu, conclui que a psicoterapia não pode ser considerada uma situação de diálogo pleno, de relação eu-tu completa, pois não há igualdade de papéis. Ela é, de certa forma, unidirecional e também não é totalmente aberta, tem suas delimitações: "em palavras simples, a psicoterapia é também uma forma específica e limitada de relação" (p.59). Essa afirmação questiona o alcance da atuação do psicólogo. Para Amatuzzi (1989), a relação humana transcende muito as possibilidades de uma terapia, mas esta pode ser extremamente fecunda na medida em 
que se aproxima de um relacionamento pessoa-pessoa. Pode-se observar posição semelhante em Rogers (1983), quando afirma que a terapia será mais fecunda quanto mais se aproximar de uma relação eu-tu verdadeira.

\section{A psicoterapia dialógica}

Amatuzzi (1989) e Hycner (1995) refletem sobre as aproximações entre a filosofia de Buber e a psicoterapia, enfatizando a importância do diálogo genuíno. Para Hycner (1995), criador do termo "psicoterapia dialógica", foi fundamental perceber que, ao falar do aspecto inter-humano, Buber se referia a algo muito maior do que o psicológico. Ao ultrapassar os campos interpessoal e intersubjetivo, apontava para a dimensão ontológica, buscando contemplar a relação humana em sua totalidade.

Incluir essas considerações na clínica psicológica contribui no sentido de não olhar apenas para o ato psíquico que se mostra, mas buscar apreender a pessoa na sua dinâmica existencial, vivenciando o "entre", ou seja, incluindo a relação e sua imprevisibilidade como fundantes no processo desencadeado. Está pressuposto aqui que o psicólogo pode ajudar o seu cliente a se aproximar daquilo que lhe é mais próprio e a buscar sua singularização através do exercício da relação. Esta, conforme postulada por Buber, não pode ser controlada e forjada de acordo com o desejo dos participantes, pois é um acontecimento, porém certa postura e disposição diante do outro facilitam sua aproximação, abrindo caminho para o encontro real entre pessoas. Tal encontro começa com o exercício de um diálogo genuíno, entendido neste trabalho como o diálogo que parte da consideração das necessidades ontológicas da pessoa, cuidando para que estas não sejam bloqueadas. Neste processo, alguns pontos fundamentais devem ser observados.

A primeira condição para um diálogo genuíno é a autenticidade dos participantes, ou seja, a possibilidade de as pessoas se guiarem pelo que são no momento, sem querer parecer algo ou produzir uma imagem de si. A este respeito, Rogers (1983) e Miller (1997) enfatizam que agir a partir de uma imagem não corresponde à plenitude do ser e, portanto, gera frustrações ao longo da vida. É um desafio colocar-se diante 80 do cliente como se é e encorajá-lo a fazer o mesmo.
Quando o psicólogo se deixa afetar pelo seu cliente, ele já não se comporta a partir de um esquema estabelecido anteriormente, mas se torna responsável pelas decisões que toma na condução do processo. Isso implica menor controle da interação e, portanto, maior vulnerabilidade. Assim, mesmo que este movimento leve ao crescimento, pode amedrontar tanto o terapeuta quanto o cliente, pois pressupõe a abertura ao novo e, assim, a transformação de si mesmo diante do outro.

A segunda condição é perceber o outro enquanto alteridade, na sua singularidade, totalidade e concretude. É ter uma atitude de contemplação, e não de mera observação. Segundo Amatuzzi (1989), a contemplação de Buber aproxima-se da observação fenomenológica e busca captar o fenômeno naquilo que ele "fala", pois ele "comunica" algo. "A fala no contexto do diálogo genuíno é também uma fala proveniente da totalidade do ser" (p.45). Ou seja, a conversação que emerge no encontro abre para uma fecundidade, que possibilita o surgimento da fala viva, polissêmica, com o aparecimento de novos sentidos.

A terceira condição é que nenhum dos parceiros queira se impor ao outro. Há uma confirmação da pessoa, o que pode ser definido como sua legitimação enquanto interlocutor do mesmo nível. Confirmar alguém é acreditar nele enquanto pessoa, sem ter que, necessariamente, concordar com ele.

O inter-humano pode desabrochar a partir dessa abertura, sendo grande a responsabilidade do psicoterapeuta, que deve fazer o possível para desenvolver tais atitudes. Amatuzzi assinala que "se eu não tiver a quem falar e que me ouça totalmente, eu não me expresso e, consequentemente, não atualizo o meu ser" (Amatuzzi, 1989, p.172, grifos do autor). A palavra, enquanto gesto fundador de mundos, reveste-se de fundamental importância, apesar de não ser a única forma de dialogar: olhares, gestos, sentimentos fazem parte da dança rítmica construída por terapeuta e cliente durante a sessão.

O terapeuta tem sua responsabilidade no desencadeamento desse processo, mas isso não significa onipotência ou controle. A clareza de sua proposta abre caminho para o surgimento de uma terceira força que age na terapia, o "entre", que é apontado nas palavras de Mahfoud (1989): "Não sou eu - por mim mesmo - que consigo que o outro faça certo caminho e mude, se 
abra e se centre. Não é nem o outro por si mesmo - tanto que pede ajuda. Mas cada um participa com o que é, terceiro elemento, integra e compõe um movimento" (p.574).

Encontrar o outro sempre provoca algo existencialmente, pois envolve uma expectativa que acaba se contrapondo ao novo que se apresenta, gerando um estranhamento que pede um posicionamento. Simão (2004) denomina esse tipo de experiência de "inquietante" e afirma que exige novos contornos para ser significada e incorporada à vida da pessoa. Para esta autora, "a importância do diálogo está, portanto, em se constituir em oportunidade para experimentar, por intermédio do outro, a possibilidade do diverso" (p. 22).

Segundo Zuben (2003), Buber se colocava constantemente na posição que denominava de "estreita aresta", buscando representar a instabilidade e insegurança próprias do existir. É difícil permanecer no lugar da incerteza, da pergunta, da abertura ao novo. A ansiedade em dar respostas e achar soluções muitas vezes afasta as oportunidades de crescimento, bem como a região de mistério que envolve cada ser. $A$ proposta da fenomenologia também procura sempre abordar os diversos lados do real, contemplando-os no seu movimento incessante, na tensão gerada no contato com o novo, com o outro.

\section{O encontro}

O desenvolvimento de uma escuta cuidadosa, atenta e a crítica visa ao estabelecimento de uma relação diferenciada, dialógica, que abra caminho para a possibilidade de uma relação eu-tu, um encontro verdadeiro, mesmo que fugaz. Mas, afinal, o que é o encontro? Qual o objetivo desse encontro em uma relação profissional, que é a psicoterapia? Quais as consequências para o cliente de se trabalhar neste enfoque?

A partir da companhia verdadeira do terapeuta, a pessoa pode se arriscar a mergulhar no seu próprio processo, pois não está sozinha. Suas experiências serão acolhidas e acompanhadas pelo psicólogo que, estando presente e atento, poderá contribuir para sua compreensão, indo além delas, indo para onde apontam. Desencadeia-se um movimento, assume-se uma tarefa e um risco. As palavras de Mahfoud (1989) resumem o que foi abordado anteriormente: "tratam-se de certas condutas do eu que facilitam ao outro colocar-se num certo mo- vimento de busca e de maior clareza e integração de si - e é um processo que acontece numa relação, ou seja, não é promovido por uma nem por outra pessoa, mas acontece, é facilitado naquela relação que também vai se transformando a cada movimento das pessoas" (p. 547, grifos do autor).

Desta forma, o encontro não é o objetivo final da terapia, mas parte desta. Para Safra (2004b), o encontro não é a resposta: é o início da caminhada, servindo para que a pessoa se coloque em trânsito, em devir. A intensidade do envolvimento presente na relação é o combustível do encontro, no qual algo novo é formulado, rompendo o cotidiano e pondo-se em marcha. Assim, a partir daí, um saber é produzido e uma pergunta é construída e apresentada pelo cliente. É importante assinalar o caráter da resposta que surge dessa indagação: ela não fecha, não responde simplesmente, cessando os questionamentos, mas abre para novas formulações, novas questões (Mahfoud, 2002). Uma resposta que surge de uma pergunta nascida do encontro, quando corresponde à vivência da pessoa, a colocará em movimento reflexivo e vivencial, tendo como resultado a apropriação de um saber sobre si. Isso explicita a relação da pessoa com o mundo e a expande, apontando para o lugar onde o homem de fato se situa: na fronteira entre sua subjetividade e o mundo, atravessada por ambos, mas irredutível a qualquer esfera. Tudo isso ressalta a natureza do encontro, posto que ele não é um fenômeno intrapsíquico, e sim relacional, impulsionando o processo compreensivo da pessoa. Assim podem ocorrer elaborações, ressignificações e a busca pelo sentido, as quais não se darão necessariamente no setting terapêutico, mas como consequência de uma relação que se refletirá na vida da pessoa também fora daquela situação específica.

Certamente, uma dimensão de mistério está presente em todo este processo, que pode ser vivido, sentido, mas não plenamente explicado. Segundo Mahfoud (1989), a chave simples e potente para manter em marcha o movimento do cliente é admirar-se, maravilhar-se com esse processo, que se mostra velado e revelado ao mesmo tempo.

\section{Considerações Finais}

Ao adotar uma determinada concepção de homem, o psicólogo assume um lugar epistemológico, 
que exige esforços teóricos e metodológicos que viabilizem o trabalho terapêutico. A concepção buberiana da relação, aliada à proposta fenomenológica de compreensão do homem e da realidade, aponta para a necessidade de a psicologia fundamentar a clínica no impulso inerente ao humano de singularizar-se e colocar-se em movimento na presença de um outro. Na perspectiva aqui apresentada, a pessoa é vista como totalidade articuladora de sentidos, dotada de uma estrutura ontológica específica que se realiza em relação. Desta forma, o olhar do terapeuta se volta para o cliente enquanto se oferece ao encontro, colocando-se ao seu lado no processo, com abertura para viver uma relação eu-tu, caso ela aconteça. Ao mesmo tempo, há grande atenção para os aspectos do diálogo em curso, com rigor e cuidado com os conteúdos que se mostram, mas não em detrimento da pessoa que os vivencia. Tal processo envolve o cliente como um todo: corporal, psicológica, social e espiritualmente. Desta forma, buscar o encontro pessoa-pessoa na clínica, assim como foi apresentado, consiste em um grande desafio, pois acaba ultrapassando as delimitações clássicas da psicologia. Torna-se necessário estabelecer pontes com filósofos que iluminem a compreensão de certos aspectos do humano, traduzindo-os para o campo psicológico, com semelhanças e limites, no âmbito da experiência individual.

Na prática clínica, segundo este enfoque, ao almejar o cuidado com o outro na sua totalidade, a ênfase está na interação e, simultaneamente, na elaboração individual que é própria da dimensão espiritual da pessoa, sempre em processo de atribuição de sentidos. Assim, a psicoterapia deve enfatizar como isso se dá mediante a vivência do encontro, seguida de elaborações resultantes da compreensão desencadeada no processo. As considerações de Buber e dos fenomenólogos aqui citados dão maior visibilidade ao movimento presente nas relações humanas em geral e buscado na clínica proposta neste trabalho.

Mesmo com todas as dificuldades teóricas e metodológicas inerentes ao campo das abordagens fenomenológico-existenciais, estas reflexões reforçam a possibilidade de construir uma psicologia mais humana, ou seja, de exercer o que há de mais humano quando se faz psicologia: entregar-se a um encontro, com interesse genuíno por quem compartilha aquela relação, buscando compreendê-la.

\section{Referências}

Ales Bello, A. (2004). Fenomenologia e ciências humanas. Bauru: EDUSC.

Amatuzzi, M. M. (1989). Oresgate da fala autêntica:filosofia da psicoterapia e da educação. Campinas: Papirus.

Arendt, H. (2002). A vida do espírito: o pensar, o querer, o julgar (5a ed.). Rio de Janeiro: Relume Dumará.

Augras, M. (1986). O Ser da compreensão: fenomenologia da situação de psicodiagnóstico. Petrópolis: Vozes.

Buber, M. (2001). Eu e tu (8a. ed.). São Paulo: Centauro. (Originalmente publicado em 1923)

Critelli, D. M. (1996). Analítica do sentido: uma aproximação e interpretação do real de orientação fenomenológica. São Paulo: Brasiliense.

Hycner, R. (1995). De pessoa a pessoa: psicoterapia dialógica. São Paulo: Summus.

Mahfoud, M. (1989). O eu, o outro e o movimento em formação. In Sociedade Brasileira de Psicologia (Org.), Anais da XIX Reunião Anual da Sociedade Brasileira de Psicologia (pp.545-549). Ribeirão Preto, SP.

Mahfoud, M. \&, Coelho Junior, A. G. (2001). As dimensões espiritual e religiosa da experiência humana: distinções e inter-relações na obra de Viktor Frankl. Psicologia USP, 12 (2), 95-103.

Merleau-Ponty, M. (1999). Fenomenologia da percepção (2a. ed.). São Paulo: Martins Fontes. (Originalmente publicado em 1945)

Miller, A. (1997). O drama da criança bem dotada. São Paulo: Summus.

Rogers, C. R. (1983). Um jeito de ser. São Paulo: EPU.

Safra, G. (2004a). A po-ética na clínica contemporânea. Aparecida: Ideias \& Letras.

Safra, G. (2004b). Estudo sobre Santa Tereza. São Paulo: Curso ministrado na Pós-graduação em Psicologia Clínica, PUC-SP (manuscrito).

Simão, L. M. (2004). Semiose e diálogo: para onde aponta o construtivismo semiótico cultural? In M. T. C. C. Souza (Org.), Os sentidos de construção: o si mesmo e o mundo (pp.13-24). São Paulo: Casa do Psicólogo.

Zuben, N. A. (2003). Martin Buber: cumplicidade e diálogo. Bauru: EDUSC.

Recebido em: 8/5/2008

Versão final reapresentada em: 10/3/2009

Aprovado em: 26/5/2009 